\title{
West Germany: a nuclear incident every three days
}

OVER the past two years, one incident or accident has occurred on average every three days in West German nuclear power stations, according to a recent report of the Bundesverband Bürgerinitiativen Umweltschutz e.v. (BBU), the chief organisation of German environment protection groups and associations. The report, "Accidents in German Nuclear Power Stations. Publication of Confidential Incident Reports of the Federal Government"', also claims that most of these incidents have been kept secret. Information for the report was obtained from the files of the Gesellschaft für Reaktorsicherheit (GRS), the German Reactor Safety Society.

Publication of the BBU report came shortly after the German Minister for Research and Technology, Volker Hauff, released part $\mathrm{A}$ of the report of a risk study of nuclear power stations in West Germany - the German version of the Rasmussen Report. The study concluded that the probability of an accident is extremely low. Ironically, the author of the study is the GRS, the very same society from which the BBU obtained its information.

GRS is a limited liability company based in Cologne with the Federal government, Bavaria, Northrhine-Westphalia, some technical supervisory bodies and the German Lloyd (an insurance company) as shareholders. In 1974/75, the Federal Ministry of the Interior commissioned the GRS to collect and categorise all data relevant to incidents and accidents in German nuclear power stations (and also, as far as possible, in foreign ones). The aim was to improve safety by mutual exchange of information between utilities and concerned authorities.

In fulfilling this commission, the GRS obtains short standardised reports from the utilities which have been prepared whenever deviations from routine operations have occurred. The deviations or incidents (besondere Vorkommnisse) are divided into three categories according to their significance for the safety of the plant and the public:

- Category A includes incidents that immediately threaten safety, for example: emission of more than the maximum permissible amount of radioactivity; breakdown within the primary circuit combined with emission of radioactivity or with coolant leakage.

- Category B includes incidents that are a potential threat to safety, for example: unplanned emission of radioactivity below permitted amounts; breakdown of system components with importance for safety during tests (if not during normal operations).

- Category C includes any other kind of deviation from specified norms and safety regulations.

The utilities themselves categorise individual incidents so that the GRS simply list the collected data and sends both the incident lists and the individual incident reports four times a year to the Ministry of the Interior, and its other shareholders.

It was these lists and reports from 1965 to autumn 1977, that the BBU has published together with a few comments, interpretations and supplements from other sources. Its report is not easy for the uninitiated to understand, because no systematic interpretation has been done, incidents of differing relevance being catalogued only by time and location. But it is a unique source of information in West Germany. In the introduction, the BBU compares the official risk study report with the confidential lists and incident reports. It concludes that the public has been misinformed on the number of incidents which have occurred. For example in 1976 according to GRS data 139 incidents, 24 in category A, 85 in category $\mathrm{B}$, and 30 in category C occurred. A Federal Government document, however, called "On the peaceful use of nuclear energy" mentions only 14 incidents in 1976, six in category $\mathrm{A}$, six in category $\mathrm{B}$, and two in category $\mathrm{C}$. The $\mathrm{BBU}$ also concludes that the public has been misinformed on the "quality" (degree of danger) of certain incidents. It compares the text of a few incident reports (written by the utilities concerned) with assessments of the same incident by other authorities (e.g. technical supervisory authorities). According to BBU a few of the incidents during 1965-1977 came fairly close to a "GAU" (greatest accident to be expected).

The BBU report calls on the Ministry of the Interior to publish all incident reports from autumn 1977 to now, and to provide quarterly, unabridged publications in future. Only then it says, can a rational public discussion take place. It also says that the number of incidents and their type prove that nuclear energy is not safe and it calls for a cessation of operation at all nuclear power stations.

Confronted with these reproaches and

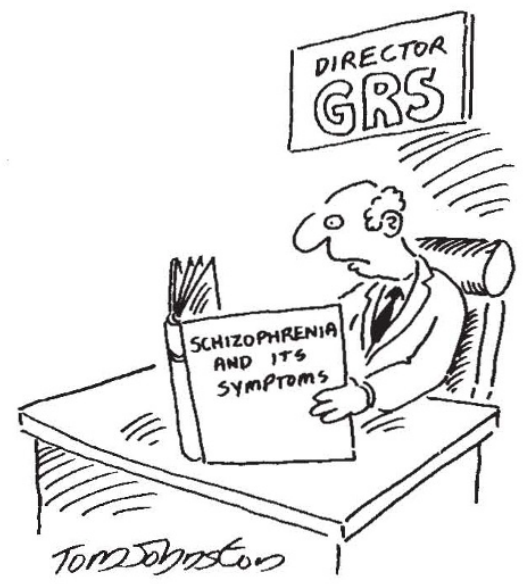

demands, the Federal Ministry of the Interior reacted almost too calmly. It said that the Bund and Länder have been informing the public of all relevant incidents in German nuclear power stations since 1966 and that Parliament is continually informed of all incidents (not only those with safety relevance). Public information is given only on incidents that threaten the safety of a power station and/or the public according to "expert assessment". The 14 incidents, mentioned in the Federal Government's documentation for 1976 are according to the ministry, "representative" and not the total number of incidents.

According to competent experts within the Federal Ministry of the Interior, there is confusion over nuclear information in the FRG revealing a lack of competence and a lack of political awareness that the public must be totally and regularly informed. There is the unique situation in the FRG, that the utilities possess a kind of "copyright" over incidents. This stems from the "Gewerbeordnung" (trade and manufacturing ordinance) a law made for small manufacturers and the "Atomgesetz" (law on nuclear energy). Both are influenced by the same ideas on 'rights of possession'. There is, therefore, no absolute compulsion on the Bund or Länder to publish information on incidents, except where it serves to improve safety conditions (as stated in the "Atomgesetz").

The prime responsibility for nuclear incidents, however, rests with the Länder. The Federal Government, represented by the Ministry of the Interior has only certain supervisory rights over the relevant Länder ministries although it has to inform the Bundestag. Now the Länder provide information on each incident. This used to be done by the Federal Ministry of the Interior before $1976 / 77$, when a first list of incidents (compiled originally for the competent committee of the Bundestag) was published in the ministry's journal Umwelt (environment). The list, however, was not complete and the individual incident reports were not published possibly because of the utilities' "copyrights"'. As was explicitly said, the list was only "representative".

There now exists an extension to the list for 1977 and 1978. It went to the competent committee of the Bundestag at the end of May 1979 and will be published in Umwelt on 12 October. Is this chance or a consequence of the BBU publication? A spokesman for the ministry claimed that "publication was planned long ago, it had to be prepared before the summer recess". The ministry now says that there are no intentions of publishing quarterly or regular lists of incidents or of publishing the individual incident reports made by the utilities.

Klaus Höpfner 